\title{
Comparative analysis of macrophage associated vectors for use in genetic vaccine
}

\author{
Mohammad Feraz Ahsan and Milind M Gore
}

\begin{abstract}
Background: Antigen presentation by non professional antigen presenting cells (APC) can lead to anergy. In genetic vaccines, targeting the macrophages and APC for efficient antigen presentation might lead to balanced immune response. One such approach is to incorporate APC specific promoter in the vector to be used.

Methods: Three promoters known to be active in macrophage were selected and cloned in mammalian expressing vector (pAcGFP1-N1) to reconstruct (pAcGFP-MS), (pAcGFP-EMR) and (pAcGFP-B5I) with macrosialin, Emrl and Beta-5 Integrin promoters respectively. As a positive control (pAcGFP-CMV) was used with CMV promoter and promoterless vector (PAcGFP-NIX) which served as a negative control. GFP gene was used as readout under the control of each of the promoter. The expression of GFP was analyzed on macrophage and non-macrophage cell lines using Flow cytometry and qRT-PCR with TaqMan probe chemistries.

Results: All the promoters in question were dominant to macrophage lineage cell lines as observed by fluorescence, Western blot and quantitative RT-PCR. The activity of macrosialin was significantly higher than other macrophage promoters. CMV promoter showed 1.83 times higher activity in macrophage cell lines. The expression of GFP driven by macrosialin promoter after 24 hours was 4.40 times higher in macrophage derived cell lines in comparison with non macrophage cell lines.
\end{abstract}

Conclusions: Based on this study, macrosialin promoter can be utilized for targeting macrophage dominant expression. In vivo study needs to be carried out for its utility as a vaccine candidate.

\section{Background}

DNA vaccination, wherein plasmid DNA encoding the desired antigen is inoculated in the host is thought to be one of the best approaches to combat several challenging diseases. The DNA thus elicits both the arms of immune response following in vivo expression of the antigen [1]. It has been endeavoured for the treatment of autoimmunity [2], cancer [3], allergic diseases [4] bacterial infections [5] and viral diseases [6]. Several strategies have been proposed to improve the efficacy of DNA vaccine, such as the use of liposomes [7], inclusion of CpG motif [8], administration of plasmid expressing costimulatory molecules and cytokines [9], exploring different routes of administration of vaccine [10-12] and targeting the vaccine to specific cells [13]. Targeting of DNA to endoso$\mathrm{mal} /$ lysosomal compartment has also been explored to enhance the immune response [14].

\footnotetext{
* Correspondence: gore.milind@gmail.com

National Institute of Virology, Pashan Campus, 130/1, Sus Road, Pashan, Pune, 411021, India
}

Successful immune response requires engagement of $\mathrm{T}$ cell receptor with MHC-peptide on professional antigen presenting cell (APC) as a first signal. Simultaneously second signal in the form of various costimulatory molecule engagement is necessary for sustained immune response. Failure to have this second signal may lead to reduced immune response or even anergy [15]. In DNA vaccines, expression of antigen in non APC cells might lead to such an outcome. In order to achieve the APC specific expression is to target the antigen expression in professional APC. For the treatment of HIV-1, APC have been targeted through ex vivo priming by expressed antigen and reinoculation [16]. Another approach is to target the expression to APC without expression in non APC cells, which could be achieved by using promoters active only in APC [17]. Dendritic cell as an APC has gained major attention over macrophage and $B$ cells as a potent cell in priming and stimulating naïve $\mathrm{T}$ cells. Langerhans cells have been targeted by Dectin-2 promoter [18]. Lentiviral vectors were also studied to deliver the gene into 
APCs [19]. CD11c promoter was widely studied as a DC selective promoter [20].

Though DC specific promoter has shown promising results, it also has some inconsistencies. In an immunization study, DC restricted DNA vaccine could not generate either humoral or cellular response and the role of B cell in cross presentation of antigen was thought to be responsible [21]. Moreover, a study has reported that targeting of $\mathrm{DC}$ was insufficient to optimally induce $\mathrm{T}$ cell immunity and the role of non-DC needs to be explored for sustained effector functions during DNA vaccination [22]. Hence the role of other professional APC (Macrophage and B-cells) as a target cell for DNA vaccine could not be ignored. It has been shown that macrophages are potent enough to stimulate naïve CD8 T cells to proliferate and mature [23]. In vitro studies have shown that macrophages are as good as DC in cross presentation of antigen [24], B cells have been shown to prime naïve CD4 T cells [25]. Thus there is a need to explore promoters which could be active also in other cells of APC and just not a single population.

The current study is aimed at ex vivo evaluation with a comparative account of macrophage dominant promoters in reference to widely used CMV promoter. Such promoters were selected on the basis of their expression profiles and association with activation following antigen encounter. GFP based reporter system was exploited due to its comparable sensitivity as the luciferase system and can be used to monitor expression of cells with low transfection efficiency [26]. Such expression studies of DNA vaccine to limited cells could also help us to improve the safety in clinical implication.

\section{Methods}

\section{Cloning}

Plasmid used in the study was pAcGFP1-N1 (Clonetech, Takara, USA) which has CMV as an immediate early promoter and GFP as a reporter (pAcGFP-CMV). Promoters were selected based on the published data. For the construction of various promoter constructs, RAW 264.7 cell line was used for genomic DNA isolation (Tri-reagent, $\mathrm{MRC}$ ) and subsequently used to amplify promoters from sequences [GenBank: AF039399], [GenBank: AJ295275] and [GenBank: AF022111] for macrosialin, Emr I and Beta-5 Integrin respectively using primers (Table 1 ). The restriction sites for insertion in the plasmid were included in primers as indicated. Respective amplicons were cloned in StrataClone ${ }^{\mathrm{TM}}$ PCR Cloning kit (Stratagene,USA) and digested with the sets of restriction enzymes (Table 1).

pAcGFP-CMV was digested with VspI/Eco47III restriction enzymes to excise CMV promoter. The digested products were cloned to reconstruct the respective vector. Promoterless vector (pAcGFP-NIX) for negative control was created by excision of CMV promoter using VspI/Eco47III sites and self ligated after klenow treatment. All reconstructed clones were confirmed through restriction analysis and sequencing.

Plasmids were prepared using Qiagen Maxiprep, according to manufacturer's protocol. The quantity and quality of plasmids was assessed using nanodrop by light absorption at $260 / 280 \mathrm{~nm}$ ratio and by $1 \%$ agarose gel electrophoresis. All the plasmids were dissolved in nuclease free water. The overall strategy of cloning and construction of plasmids with specific promoters is shown in Figure 1.

\section{Cell culture}

RAW 264.7 (National Center for Cell Sciences, Pune, India) was maintained in high glucose DMEM with $10 \%$ fetal bovine serum (FBS) (Gibco, USA). This cell line was selected as a model to study expression in mouse macrophage cell lines [27]. L929 was obtained from the American Type Culture Collection (Rockville, MD) and maintained in MEM (Sigma) with 10\% FBS. This cell line served as a modality to study expression in nonmacrophage cell [28]. All cultures were incubated at $37^{\circ}$ C, $5 \% \mathrm{CO}_{2}$ in humidified environment. Antibiotic free media were used during transfection and for regular maintenance of cells.

Table 1 Primers used for cloning to amplify promoters with underlined restriction sites.

\begin{tabular}{|c|c|c|}
\hline $\begin{array}{l}\begin{array}{l}\text { Promoter } \\
\text { (Constructs) }\end{array} \\
\end{array}$ & Primer Sequence $\left(5^{\prime} \rightarrow 3^{\prime}\right)$ & Restriction site \\
\hline \multirow{2}{*}{$\begin{array}{l}\text { Macrosialin } \\
\text { (pAcGFP-MS) }\end{array}$} & F-TATTAATGACCAAATCTACAGGGAGAACCC & Vspl/Eco47III \\
\hline & R-AGCGCTAGATGCTCAGACCAGCTA & \\
\hline \multirow{2}{*}{$\begin{array}{l}\text { EMR-1 } \\
\text { (pAcGFP-EMR) }\end{array}$} & F-TCATATGGAATTCTITGTITAGGTCTGTATGC & Ndel/Eco47III \\
\hline & R-TAGCGCTTACTGTGGCAGTCATTCA & \\
\hline \multirow{2}{*}{$\begin{array}{l}\text { Beta-5 Integrin } \\
\text { (pAcGFP-B5I) }\end{array}$} & F-CCGATTAATATTCAAACGCCTTAGGTAGGTIT & Vspl/Eco47III \\
\hline & R-AGCGCTTCTACTCTCGGAGACCCT & \\
\hline
\end{tabular}

F: Forward Primer, R: Reverse Primer, Underlined sequences are the restriction enzyme sites 


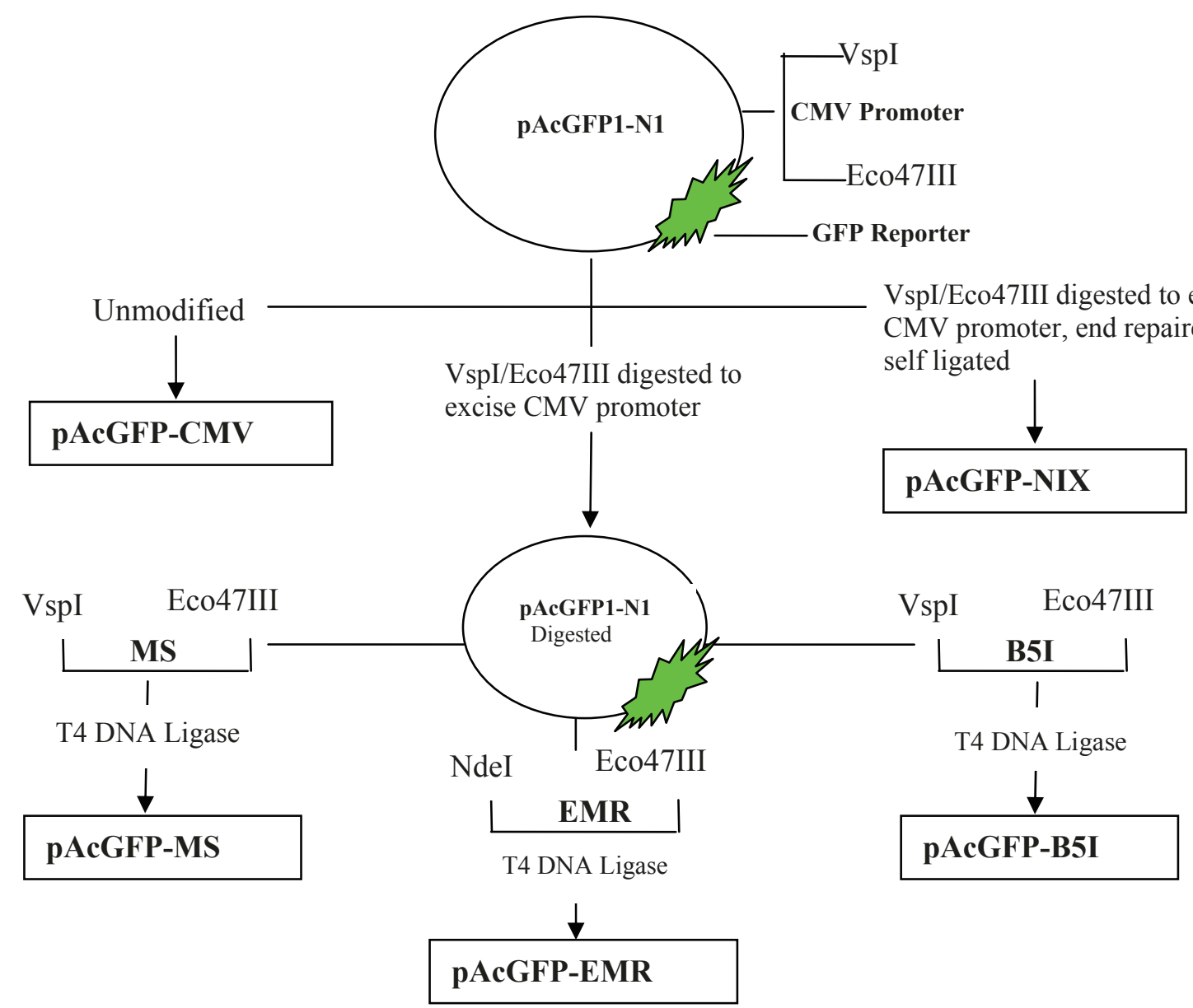

Figure 1 Schematic representation of reconstructed promoters constructs with GFP as a reporter gene.

\section{Transfection}

Newly constructed pAcGFP-CMV, pAcGFP-MS, pAcGFPEMR, pAcGFP-B5I, pAcGFP-NIX plasmids were used for transient transfection experiment. Transfections were performed using Lipofecatmine TM 2000 (Invitrogen, USA). RAW264.7 and L929 cells were harvested and seeded in 6 well plates $\left(3 \times 10^{5}\right.$ cells/well). The plate was then incubated for 16 hours and after reaching confluence was transfected using $2 \mu \mathrm{g}$ of each plasmid with $2 \mu \mathrm{l}$ Lipofectamine 2000 as per manufacturer's protocol. Opti-MEM ${ }^{\circledR}$ I reduced serum media (Invitrogen, USA) was used as a medium for transfection. Negative control was used both for Lipofectamine 2000 and plasmid DNA.

\section{Western blot}

Expression of GFP protein was analysed by Western blot using standard protocols. Briefly, 24 hours after transfection with different DNA constructs encoding GFP, RAW 264.7 cells were harvested, washed twice with PBS, mixed with an equal volume of $2 \times$ loading buffer and boiled for $10 \mathrm{~min}$. Proteins form $50 \mu \mathrm{g}$ of cell lysate were separated onto a discontinuous SDS-polyarylamide gel with 5\% stacking gel and 12\% separating gel and transferred to a nitrocellulose membrane (Amersham Biosciences, USA). The membrane was blocked by $5 \%$ skimmed milk powder in PBS and then incubated with anti-GFP Ab (1:1000, Clontech) followed by goat antimouse IgG-HRP conjugate (1:5000, Sigma). Bands were visualized with substrate solution containing diaminobenzidine tetrahydrochloride and $\mathrm{H}_{2} \mathrm{O}_{2}$ solution.

\section{Fluorescent Microscopy}

Both RAW 264.7 and L929 cells were monitored for GFP fluorescence at 6,12, 24, 36 and 48 hours post transfection under UV microscope (Nikon eclipse Ti). The setting of microscope and camera was constant throughout, so as to get the semi-quantitative analysis. The photograph was captured with following settings: Resolution- Fast; Focus-640 × 480; Quality-2560 × 1920; Mode-manual exposure; Exposure-800 ms; Gain-1.20×; Objective-20x; Contrast- high. The software used for the analysis was: NIS-Elements BR version 3.1 


\section{Flow cytometry}

After transfection at different time points, cells were harvested by trypsinization, washed twice with PBS and suspended in FACS buffer (PBS + 2\% FBS and $0.1 \%$ sodium azide). All samples were analysed using FACS Calibur (Becton Dickinson) and data were analysed using CellQuest Pro (Becton Dickinson) software. 10,000 events were used for analysis. GFP was excited through argon LASER and fluorescence was captured in FL1 channel by using 530/30 $\mathrm{nm}$ bandpass filter. The debris and dead cells were excluded using FSC and SSC parameters. Mean fluorescence was used to evaluate the level of GFP expression above the threshold level of autofluorescence of non-transfected control cells. For each assay three independent transfections were performed and mean fluorescence with \pm SEM was used for analysis.

\section{Standardization of quantitative RT-PCR for detection of GFP mRNA}

\section{Primer and probe design}

Selected GFP sequences available in the GenBank were aligned using MEGA4 software [29]. Primers and probe were designed using Primer Express software ${ }^{\mathrm{TM}}$ 3.0 (Applied Biosystems International, Foster City, CA) (Figure 2). Primers and probe were picked from GFP sequence [GenBank: AY233272] nt. 196-295 with amplicon size of $100 \mathrm{bp}$. The probe was labelled with FAM (5-carboxyfluorescein) at the 5'end and BHQ-1 (Black hole quencher 1) at 3'end.

\section{Preparation of RNA standard for the $q R T-P C R$}

The $187 \mathrm{bp}$ region was amplified using primer sets (Table 2, Cloning) from vector pAcGFP1-N1 and cloned into the $\mathrm{pGEM}^{\mathbb{R}}$ - T Easy cloning vector (Promega
Corporation, Madison, USA). The orientation of the insert was confirmed by sequencing. Plasmid was linearised by SpeI restriction enzyme. Target sequence was transcribed in vitro, DNAase treated and purified by MEGAscript ${ }^{\circledR}$ kit (Ambion, USA) as per manufacturer's instructions. The RNA was quantified by spectrophotometry. The copy numbers of the RNA was calculated based on the concentration and its molecular weight. Ten fold serial dilutions of RNA from $10^{2}$ to $10^{10}$ copies per reaction were used as standard in all qRT-PCRs.

\section{qRT-PCR}

After the desired period of post transfection, total RNA was extracted from the cell pellet of RAW 264.7 and L929 cells using RNEasy kit (Qiagen, Valencia, CA) and DNAse treated as per the manufacturer's protocol. RNA was eluted in $50 \mu \mathrm{l}$ RNAse-free water and stored at $-80^{\circ}$ C. $5 \mu \mathrm{l}$ (300 ng) of total RNA was used for all qRT-PCR for transfected cells. All reactions were carried out along with standards. The assay was run in triplicates in RotorGene 3000 тм (Corbett Research, Sydney, Australia) with the following thermal steps, $\mathrm{RT}$ at $50^{\circ} \mathrm{C}$ for $15 \mathrm{~min}$, initial denaturation at $95^{\circ} \mathrm{C}$ for $2 \mathrm{~min}, 45$ cycles of denaturation at $95^{\circ} \mathrm{C}$ for $15 \mathrm{sec}$ and annealing with extension at $60^{\circ} \mathrm{C}$ for $30 \mathrm{sec}$. Fluorescence data were collected at the end of each cycle. Each reaction comprised no template control (NTC), cell control and cells treated with plasmid without transfectant. Primers and probe were used from a range of 100 to $600 \mathrm{nM}$ for optimum concentration. CT values were recorded each time. $200 \mathrm{nM}$ of forward and reverse primer with $100 \mathrm{nM}$ of probe were found to be optimal for one step qRT-PCR in $25 \mu \mathrm{L}$ final reaction volume. Optimised concentration of primer and probes were used to detect the copy number of in vitro transcribed RNA (IVT-RNA).

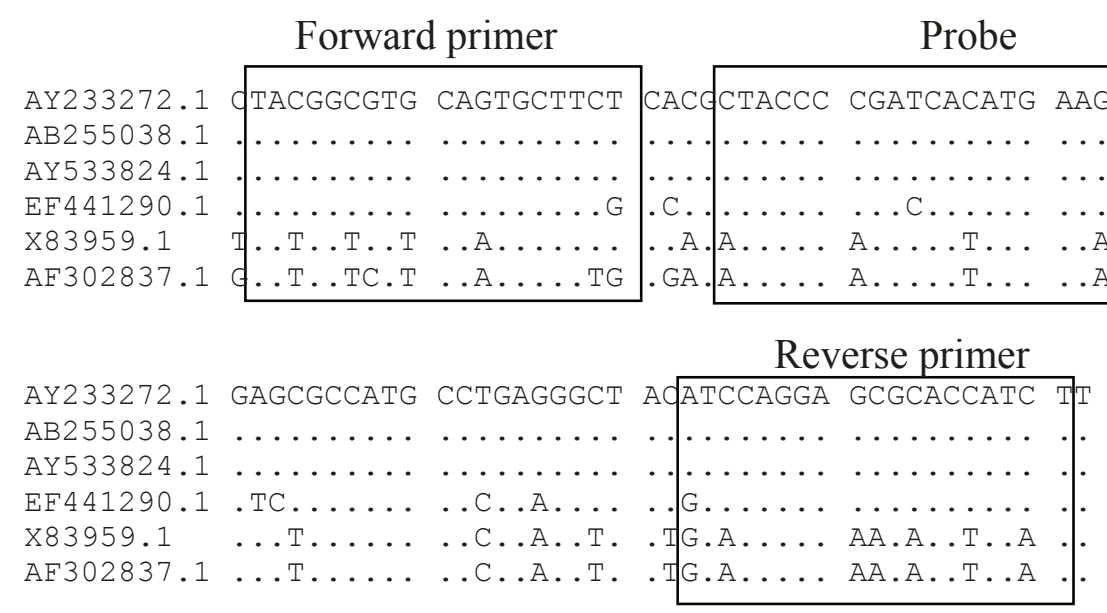

Figure 2 Sequence alignment of GFP variants in GenBank showing the location of primers and probe. GFP sequences were selected from data bank and aligned using MEGA4 software. The references of sequences are mentioned with the Accession number of GenBank. The sequence used for the primer and probe design was: Accession number-AY233272, GI-34421677. 
Table 2 Nucleotide sequence of primers and probe used in pGEM-T Easy cloning and qRT-PCR assay

\begin{tabular}{llll}
\hline Assay & Primer $/$ Probe & Sequence $\left(\mathbf{5}^{\prime} \rightarrow \mathbf{3}^{\prime}\right)$ & Nucleotide positions \\
\hline qRT-PCR & Forward Primer & TACGGCGTGCAGTGCTTCT & 196-214 \\
\hline & Reverse Primer & AGATGGTGCGCTCCTGGAT & $277-295$ \\
\hline Cloning & TaqMan Probe & CTACCCCGATCACATGAAGCAGCACG & $219-244$ \\
\hline & Forward Primer & AAGTTCATCTGCACCAC & $133-149$ \\
\hline
\end{tabular}

\section{Statistics}

All the data obtained through Flow cytometry or qRTPCR was analysed for statistical significance using General Linear model, Tukey's comparison test. Analysis was performed using SPSS version 11 software.

\section{Results}

\section{Selection of promoter}

Following promoters were selected for the studies based on their known expression profiles. Macrosialin is a glycoprotein expressed specifically in murine monocytes and macrophages, and to a lesser extent by DC [30-32]. Macrosialin is murine homologue of CD 68 sharing $80 \%$ similarity [32]. Emr-1 (EMR) promoter is reported to control its gene expression mainly in macrophages [33-35]. The human orthologue of EmrI is EMRI. The promoter of EmrI and EMRI share 60\% identity and is with purine rich conserved region. Its gene product has also served as a marker for macrophage population in many immunohistological studies [36]. Beta-5 Integrin promoter is expressed in macrophages and osteoblasts $[37,38]$. Integrin belongs to the family of type I transmembrane glycoprotein. It helps in cell migration, proliferation and differentiation. As a positive control we chose immediate early promoter of cytomegalovirus (CMV) which is widely used and is strong enough to drive constitutive expression in all cell types. As a negative control promoterless vector was constructed. This vector though has GFP as a reporter gene but is devoid of any promoter. All the selected promoters except CMV are TATA-less promoters and have PU.1 as a transcription factor which assembles the transcription machinery on myeloid promoters.

\section{Promoter amplification from genomic DNA and} expression studies of various promoter constructs Promoter sequences were amplified from RAW264.7 cells using Tri-reagent (MRC) and PCR. Amplicons obtained are shown in Figure 3. These were further used for cloning after sequence confirmation. Expression of GFP with different promoter constructs was analysed by fluorescent microscopy. Strong GFP expression was detected with pAcGFP-CMV in RAW264.7 and L929 cells, in contrast no GFP expression was observed with pAcGFP-NIX or Untransfected cells at any time point

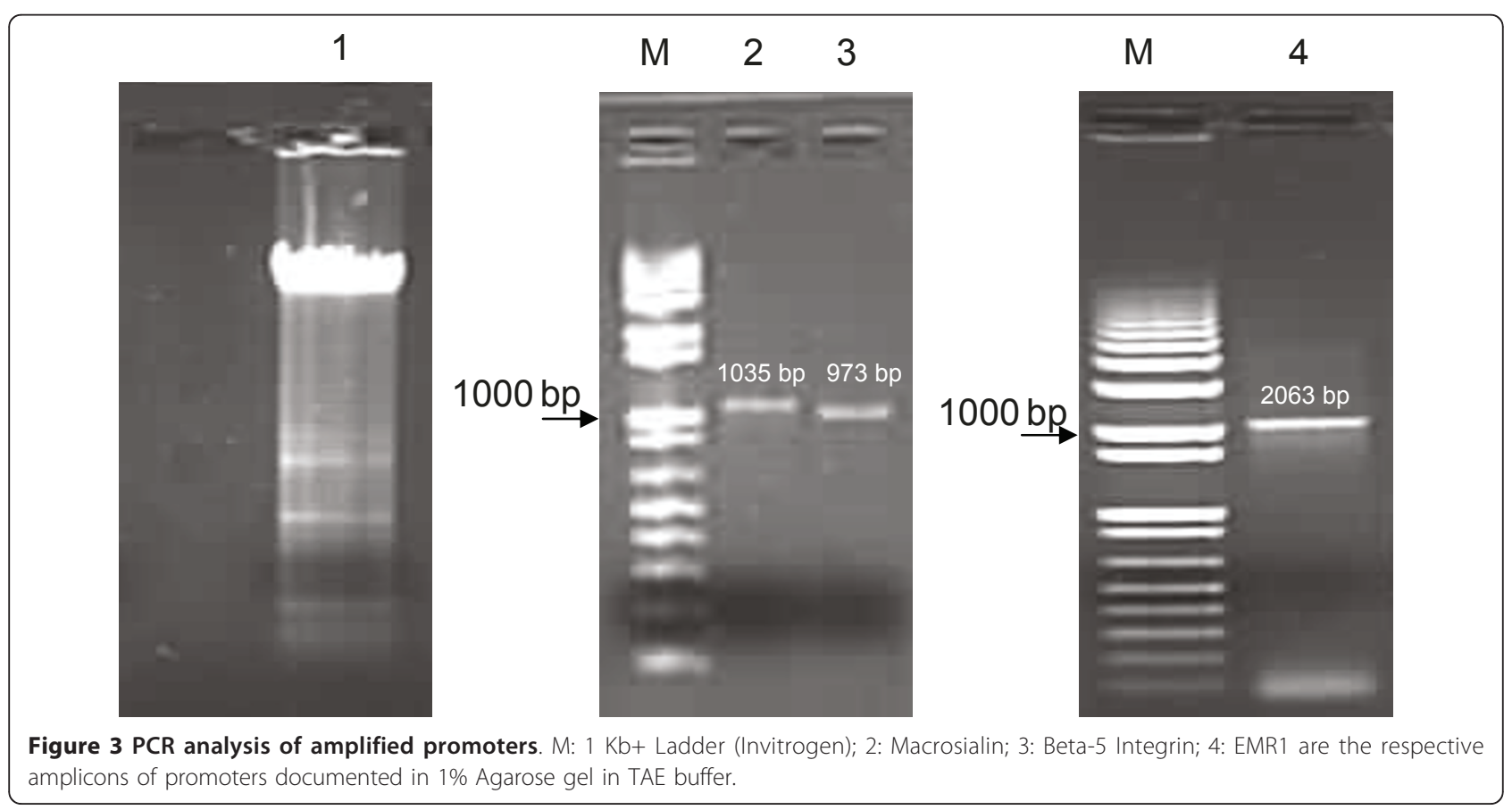


of studies (Figure 4). Figure shows representative pictures taken at different time point for each cell type (06-48 hrs following transfection) (Figure 4, A, B, C, D and $4 \mathrm{E})$. Fluorescence of cells transfected with pAcGFPMS was significantly higher than other modified constructs expressing GFP. The difference in fluorescence intensities were observed when the same constructs were used for RAW 264.7 and L929 cells. As expected non macrophage cell line L929 showed lesser expression of GFP driven by APC promoters.

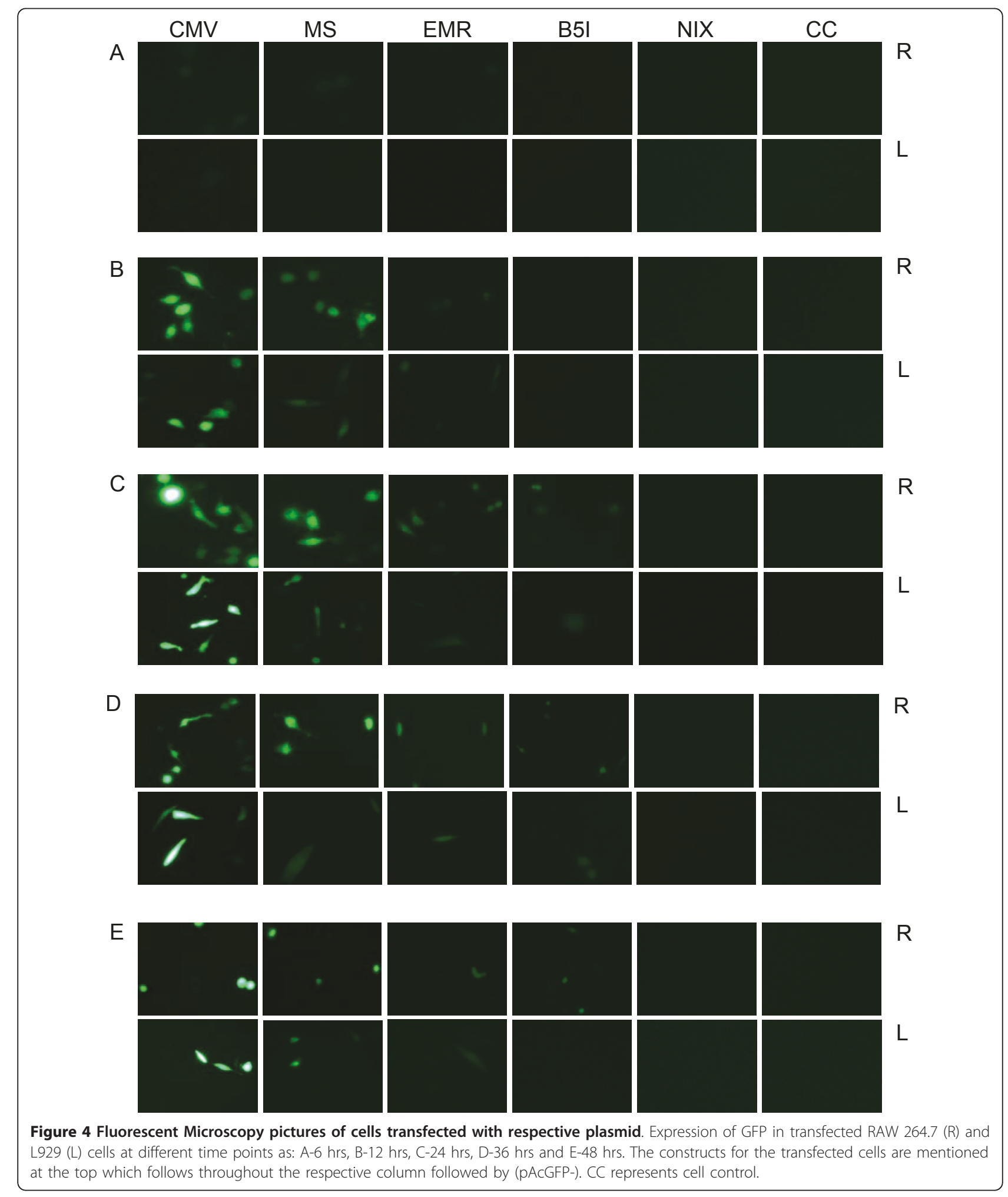




\section{Western blot}

The transfected RAW 264.7 cell lysates prepared after 24 hours post transfection were subjected to Western blot analysis. The anti-GFP monoclonal antibody reacted specifically with GFP protein of $\sim 27 \mathrm{kDa}$. Negative control did not show detectable levels of GFP. Strong expression of GFP under CMV promoter, served as a positive control (Figure 5, A and 5B).

\section{Flow cytometry analysis of GFP with different promoter constructs}

Preliminary screening was performed using fluorescent microscope, green fluorescence was observed in cells transfected with respective constructs, confirming the successful protein expression. Precise specificity and strength of the promoter constructs were evaluated by Flow cytometry through transient transfection in RAW264.7 and L929 cells. MFI of pAcGFP-CMV construct after 24 hours was 11 fold in RAW 264.7 and 8.8 fold in L929 cells over that of Untransfected cells, whereas 6 fold and 2 fold in RAW264.7 and L929 cells respectively for pAcGFP-MS (Figure 6, A and 6B). The MFI of cells transfected with different constructs was significantly higher $(\mathrm{p}<0.05)$ when compared with Untransfected cells. No significant difference was observed between pAcGFP-NIX and Untransfected cells at any time point of studies. The differential level of expression of pAcGFP-MS when compared in RAW 264.7 and L929 cells, was found to be highly significant up to 36 hours. Similarly it was significant for pAcGFP-B5I up to 48 hours and non-significant for pAcGFP-EMR at all time points. For the comparative account of promoter specificity we have also used ratio of promoter activity in macrophage to that of non macrophage cells (Figure 6C). Among the promoters under study macrosialin promoter drove the high expression of reporter gene and conferred the highest myeloid specificity. This ratio could not be taken as absolute values due to variance in transfection efficiency in both the cell lines, rather it rendered a useful index of specificity.

Studies were also carried out using P388D1 and Vero cells as a macrophage and non macrophage cells respectively. Fluorescent microscopy showed the same trend of expression with different constructs (data not shown). It was difficult to transfect P388D1 cell line when the protocol mentioned above for the other cells were followed. The efficiency of transfection was very low. Increasing the Lipofectamine 2000 concentration increased the efficiency slightly. The expression levels directed by the promoters were highest after 24 hours. Intensity of GFP expression through CMV promoter was the highest followed by macrosialin and the other two promoters, following the same trend of expression as that of RAW264.7. Similarly, expression level in Vero cells was same as L929 cells, however, they got transfected with ease. Hence we carried out our further study on RAW264.7 and L929 cells.

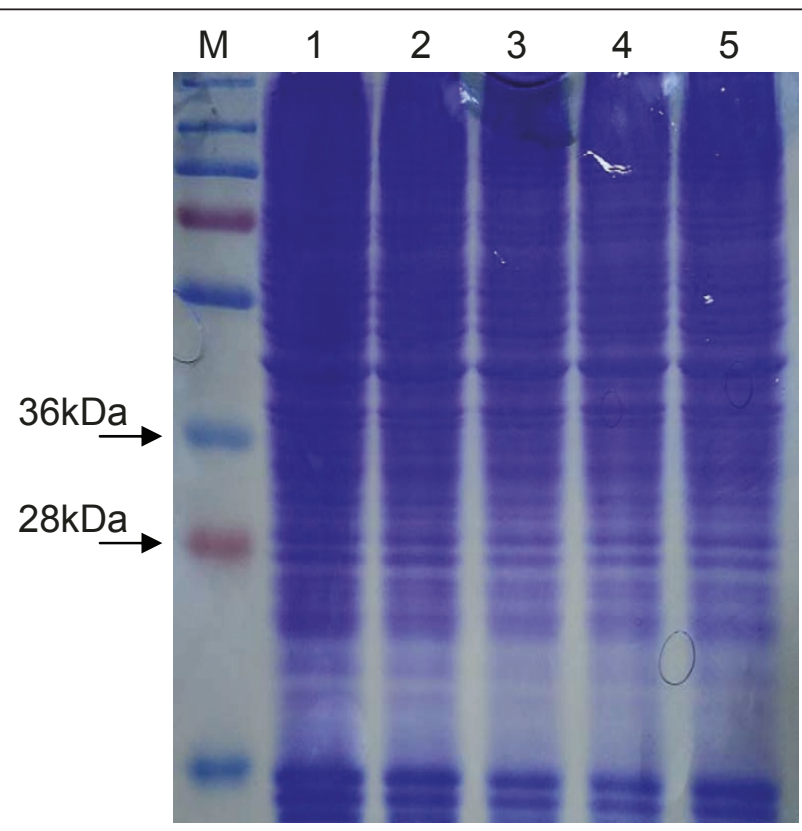

A

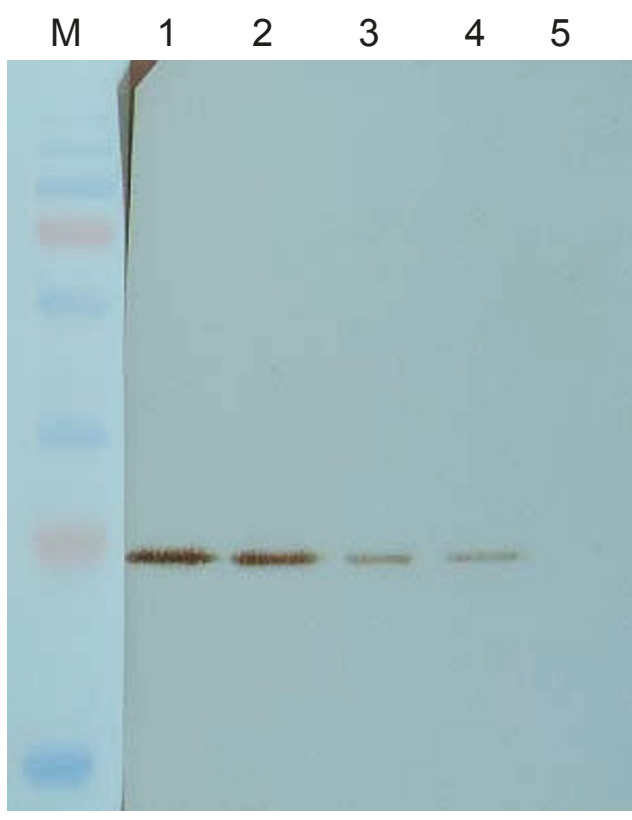

B

Figure 5 PAGE/Western blot Analysis. (A) 12\% SDS-PAGE gel (B) Western blot analysis of the total cell lysates of the RAW 264.7 cells. M: PageRulerTM (Fermentas); 1: pAcGFP-CMV; 2: pAcGFP-MS; 3: pAcGFP-EMR; 4: pAcGFP-B5I; 5: pAcGFP-NIX. The blot shows expressed GFP protein from different constructs after 24 hours of transfection. 


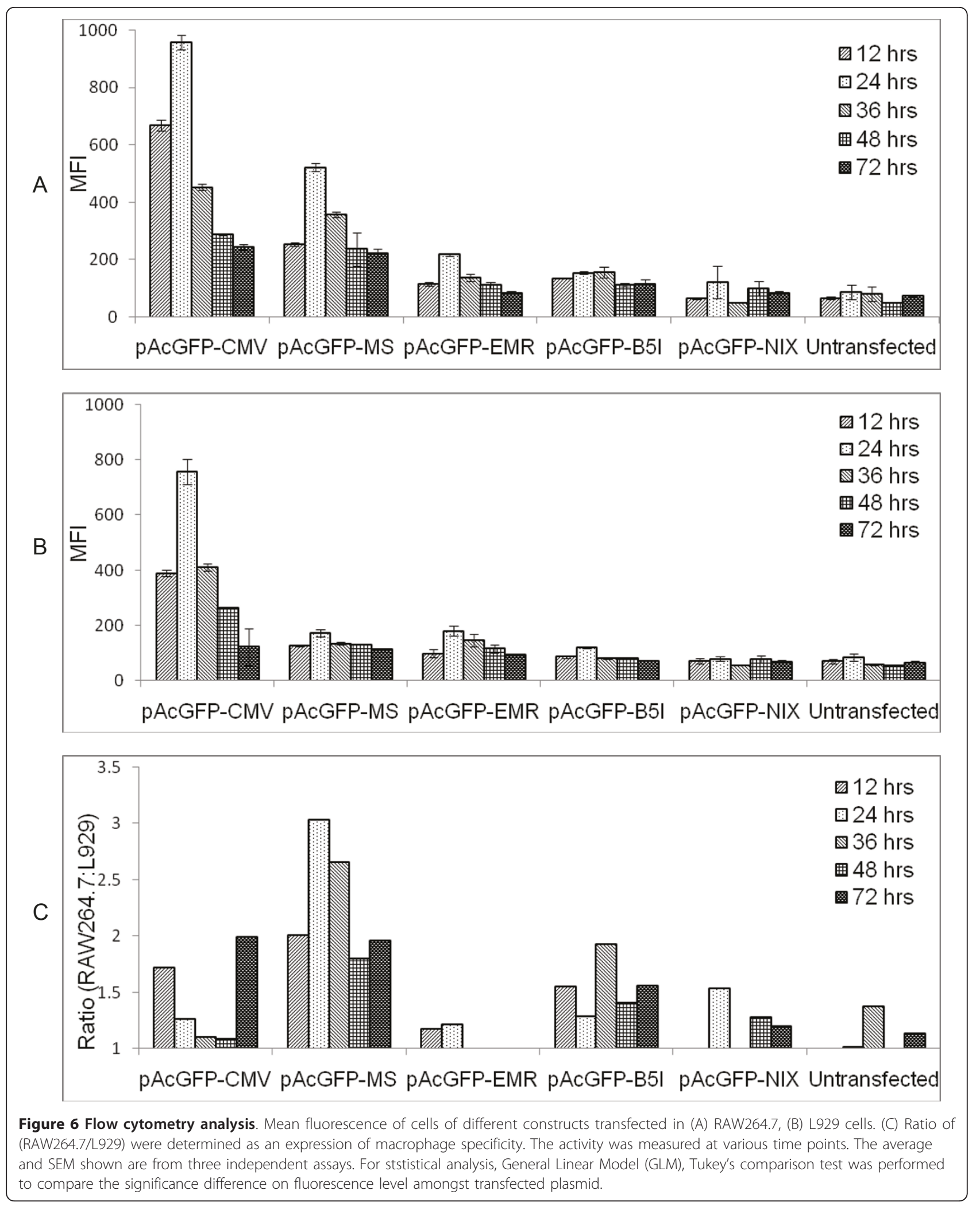




\section{Quantification of GFP in transfected cells}

The assay was sensitive enough to detect $<100$ copies of IVT-RNA (CT = 38.59). Linear correlation value in CT values obtained over the range of IVT-RNA per reaction was $\left(R^{2}=0.99\right)$, when $10^{2}$ to $10^{10}$ copies were used. The assay did not amplify any non specific sequence from cellular RNA of cells used. There were clean bands of amplicons when observed in agarose gel electrophoresis. To check the reproducibility of the assay the standards were run on six different days and similar CT values were found for the given inputs of IVT-RNA. The data is the representative of the test (Figure 7).

RNA was quantified post transfection after 12, 24 and 48 hours. It was observed that GFP in construct with CMV promoter was highly expressed in both RAW 264.7 and L929 cells $\left(5.07^{\wedge} 5\right.$ vs $\left.8.94^{\wedge} 6\right)$. The construct with macrosialin promoter showed $>36$ fold copy numbers in RAW264.7 cells in comparison to L929 cells at the end of 48 hrs. Data represented here is from analysis of three independent transfection assays with \pm SEM. One way ANOVA, Tukey's comparison test was performed to compare the GFP transcripts in cells transfected with different construct. pAcGFP-CMV and pAcGFP-MS has a significantly higher number of GFP transcripts compared with Untransfected or pAcGFP-NIX construct $(\mathrm{P}<0.05)$. We get no amplification in Untransfected and pAcGFPNIX (Figure 8, A and 8B)

\section{Discussion}

The promoters of viruses are widely used in many mammalian expression vectors due to their strong activity in large variety of cells. CMV promoter has been of choice because of high level of constitutive expression in several mammalian cell lines [39]. Constitutive expression of gene could be suitable for gene therapy or certain applications [40]. However importance of using lineage specific promoter in DNA vaccine to limit gene expression to the target cells is of paramount importance, not only as an adjuvant [41] but also as a safety concern [42].

In the present study, we have compared the activity of promoters mainly active in macrophages, delineated as a macrophage expressing promoters. GFP gene as a quantitative reporter was used to evaluate the strength of promoters. Vectors were engineered with different promoters coding GFP readout for the study. pAcGFPCMV has a strong CMV immediate-early promoter and was used as a positive control. Three (pAcGFP-MS, pAcGFP-EMR, pAcGFP-B5I) aforesaid promoter constructs with GFP reporter were compared. pAcGFP-NIX without promoter but with GFP gene was constructed as a negative control.

RAW264.7 cells (macrophage) and L929 (fibroblast) cells were selected for the study. These cell lines were selected to evaluate the behaviour of promoters in macrophage and non-macrophage cells respectively. Comparison of GFP expression through CMV promoter simultaneously in both the cells also helped us to analyze the difference in expression level due to difference in transfection efficiency.

To evaluate the activity of promoters under study, fluorescent microscopic analysis of GFP expressing cells were carried out. Fluorescence of GFP increased based on the expression which correlates to the activity of respective promoter. Besides the visual confirmation, functionality of

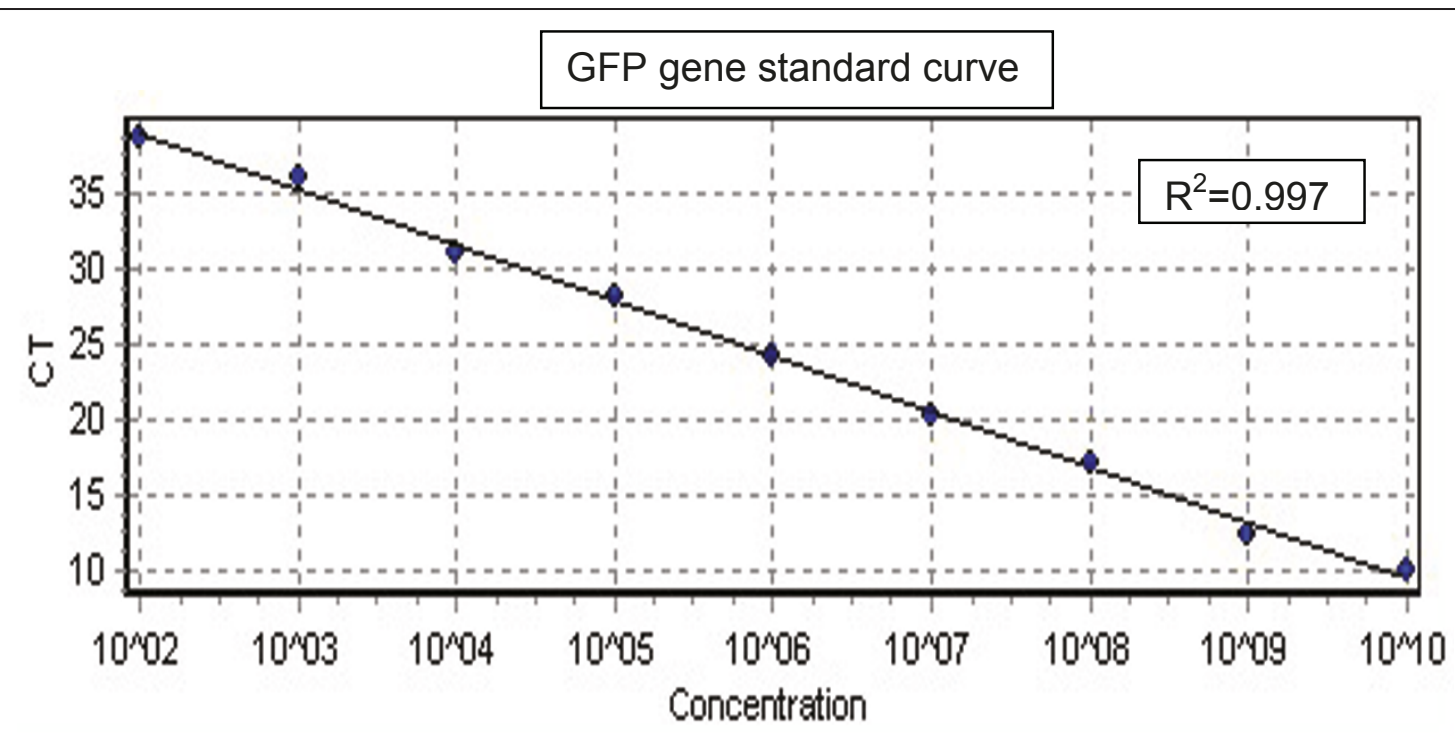

Figure 7 Standard curve plot of log10 diluted in vitro transcribed RNA for GFP. 


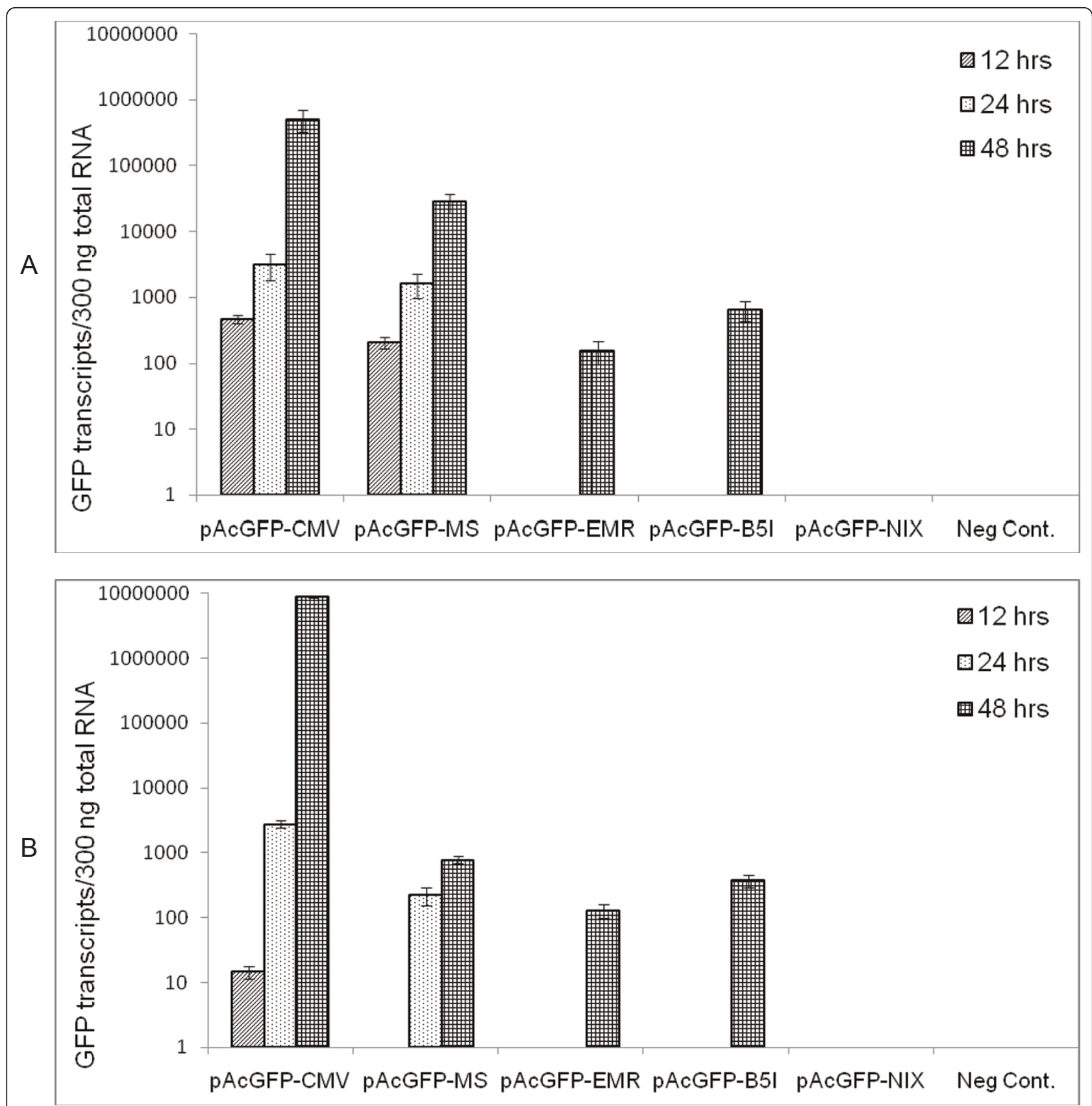

Figure 8 Transcript profiling of GFP. Transcript profiling of RAW264.7 (A) and L929 (B) cells transfected with different promoter constructs at the given time interval.

all the promoter constructs was confirmed by Western blot of GFP which agreed to the microscopic analysis.

In order to assess the expression over large population of cells and achieve more sensitive data, flow cytometry was carried out for such differential expression. Mean fluorescent intensity (MFI) which was used for data acquisition is the average of certain number of cells obtained from individual cells in the population; such analysis provides the reproducible method to quantitate changes in reporter gene expression from a population. The expression of GFP by CMV promoter was robust in both the cells at all time points in comparison to other promoters (Figure 4). Among the macrophage specific promoter expression in RAW264.7, macrosialin showed higher expression followed by the other two constructs. Kinetics of promoter activity was assessed by evaluating reporter expression at various time points after transfection. All the constructs exhibited gradual increase in activity up to 
24 hours, which decreased further. The expression of macrosialin promoter was significantly higher in macrophage cell line in comparison to non-macrophage cells. The ratio of macrophage/non-macrophage evaluation was the highest in macrosalin as an indicator of macrophage specificity. After 24 hours of analysis there was a decreasing trend in expression. The probable reason could be due to cells reaching confluence and underwent death, moreover the effect of toxicity of transfectant also increased over time. GFP fluorescence increased as per increase in protein concentration which was well depicted by Flow cytometry and fluorescent microscopy as reported earlier [43].

In order to understand the transcriptional activity of promoter, GFP mRNA levels were quantitated by one step qRT-PCR with TaqMan based probe chemistry developed in house. It supported the data obtained by Flow cytometry. Highest expression at all time point through CMV promoter was observed, followed by macrosialin. There was increasing trend in mRNA expression as per time, till 48 hours, however, after 72 hours no transcripts were detected. This difference may be attributed due to several reasons i.e. increase in level of toxicity over the time, there was no tight control over mRNA expression hence rigorous control over translation, all the mRNA were not turned into protein. The correlation at RNA and protein level depends upon the balance of transcriptional and translational regulatory elements [44]. The cessation of the expression of gene after limited expression could be beneficial for in vivo studies to avoid continued sustenance of antigen, since prolonged Ag exposure might lead to lower affinity $\mathrm{Ab}$. Thus among the promoters under study, macrosialin directed the macrophage dominant expression in terms of both transcription and translation. Macrosialin governed the highest expression when compared with either EmrI or Beta-5 Integrin promoters. Regardless of the observed difference between mRNA or protein level, our finding clearly shows that macrosialin dominantly govern the expression in macrophage derived cells. It might be possible to use this promoter for directing expression of desired protein dominantly in APC.

Successful demonstration of APC dominant expression of GFP has opened an avenue to construct plasmids with virus encoded proteins. Use of these plasmids to evaluate the effect of cell dominant expression on the immune response and indication of protective ability would be interesting. In addition, targeting macrophage for various applications including immunotherapy might also be explored.

\section{Conclusions}

To determine whether APC expressing promoters could be useful in terms of its specificity and activity, we compared with the CMV immediate early promoter in macrophage and non-macrophage derived cells. The activity of macrosialin was significantly higher in macrophage cells in comparison to EmrI and Beta-5 Integrin, whereas CMV showed the highest activity in both the cell types. Our work presents a systematic ex vivo study at the level of protein expression and mRNA transcription. This indicates that macrosialin promoter might prove beneficial for targeting expression majorly in APC, however in vivo potential needs to be carried out for its suitable application.

\section{Acknowledgements}

Ahsan MF acknowledges Indian Council of Medical Research, Government of India, for providing Senior Research Fellowship (SRF) and National Institute of Virology, Pune, for the extended fellowship. We thankfully acknowledge Dr. Bondre VP and Dr. Sapkal GN for their support and Mr. Walimbe AM for his help in statistical analysis of the data. We gratefully appreciate the intellectual discussion and suggestions by Dr. Satyendra $K$ and his kind help. We thank Dr. Gurukumar KR, Mr. Devhare P, Mr. Fulmali P for the discussion and Mr. Subhashis C for his help in Fluorescent Microscopy. We also thank Mr. Ayachit, Mr. Naidu J, Ms. Reshma, Ms. Daya, Mr. Roopesh and Ms. Harini.

\section{Authors' contributions}

MFA has planned, designed and carried out all the experiments. MMG envisioned and supervised all the studies. Both the authors read and approved the final manuscript.

\section{Competing interests}

The authors declare that they have no competing interests.

Received: 28 February 2011 Accepted: 18 June 2011

Published: 18 June 2011

\section{References}

1. Chikhlikar P, Barros de Arruda L, Maciel M, Silvera P, Lewis MG, August JT, Marques ET: DNA encoding an HIV-1 Gag/human lysosome-associated membrane protein-1 chimera elicits a broad cellular and humoral immune response in Rhesus macaques. PLoS One 2006, 1:e135.

2. Okura Y, Miyakoshi A, Kohyama K, Park IK, Staufenbiel M, Matsumoto Y: Nonviral Abeta DNA vaccine therapy against Alzheimer's disease: Longterm effects and safety. Proc Natl Acad Sci USA 2006, 103(25):9619-9624.

3. McKinney KA, Al-Rawi N, Maciag PC, Banyard DA, Sewell DA: Effect of a novel DNA vaccine on angiogenesis and tumor growth in vivo. Arch Otolaryngol Head Neck Surg 2010, 136(9):859-864.

4. Li G, Liu Z, Zhong N, Liao B, Xiong Y: Therapeutic effects of DNA vaccine on allergen-induced allergic airway inflammation in mouse model. Cell Mol Immunol 2006, 3(5):379-384.

5. Shiau JW, Tang TK, Shih YL, Tai C, Sung YY, Huang JL, Yang HL: Mice immunized with DNA encoding a modified Pseudomonas aeruginosa exotoxin A develop protective immunity against exotoxin intoxication. Vaccine 2000, 19(9-10):1106-1112

6. Tung WS, Bakar SA, Sekawi Z, Rosli R: DNA vaccine constructs against enterovirus 71 elicit immune response in mice. Genet Vaccines Ther 2007, 5:6.

7. Ishii N, Fukushima J, Kaneko T, Okada E, Tani K, Tanaka SI, Hamajima K, Xin KQ, Kawamoto S, Koff W, Nishioka K, Yasuda T, Okuda K: Cationic liposomes are a strong adjuvant for a DNA vaccine of human immunodeficiency virus type 1. AIDS Res Hum Retroviruses 1997, 13(16):1421-1428.

8. Sato Y, Roman M, Tighe H, Lee D, Corr M, Nguyen MD, Silverman GJ, Lotz M, Carson DA, Raz E: Immunostimulatory DNA sequences necessary for effective intradermal gene immunization. Science 1996, 273(5273):352-354.

9. Iwasaki A, Stiernholm BJ, Chan AK, Berinstein NL, Barber BH: Enhanced CTL responses mediated by plasmid DNA immunogens encoding costimulatory molecules and cytokines. J Immunol 1997, 158(10):4591-4601. 
10. Okada E, Sasaki S, Ishii N, Aoki I, Yasuda T, Nishioka K, Fukushima J, Miyazaki J, Wahren B, Okuda K: Intranasal immunization of a DNA vaccine with IL-12- and granulocyte-macrophage colony-stimulating factor [GMCSF]-expressing plasmids in liposomes induces strong mucosal and cell-mediated immune responses against HIV-1 antigens. J Immunol 1997, 159(7):3638-3647.

11. Sha Z, Vincent MJ, Compans RW: Enhancement of mucosal immune responses to the influenza virus $\mathrm{HA}$ protein by alternative approaches to DNA immunization. Immunobiology 1999, 200(1):21-30.

12. Livingston JB, Lu S, Robinson $H$, Anderson DJ: Immunization of the female genital tract with a DNA-based vaccine. Infect Immun 1998, 66(1):322-329.

13. Tuting T, Storkus WJ, Falo LD Jr: DNA immunization targeting the skin: Molecular control of adaptive immunity. J Invest Dermatol 1998, 111(2):183-188.

14. Ji H, Wang TL, Chen CH, Pai SI, Hung CF, Lin KY, Kurman RJ, Pardoll DM, Wu TC: Targeting human papillomavirus type 16 E7 to the endosomal/ lysosomal compartment enhances the antitumor immunity of DNA vaccines against murine human papillomavirus type 16 E7-expressing tumors. Hum Gene Ther 1999, 10(17):2727-40.

15. Felix NJ, Suri A, Salter-Cid L, Nadler SG, Gujrathi S, Corbo M, Aranda R: Targeting lymphocyte co-stimulation: from bench to bedside. Autoimmunity 2010, 43(7):514-525.

16. Lori F, Kelly LM, Lisziewicz J: APC-targeted immunization for the treatment of HIV-1. Expert Rev Vaccines 2004, 3(4 Suppl):S189-198.

17. Ni J, Nolte B, Arnold A, Fournier P, Schirrmacher V: Targeting anti-tumor DNA vaccines to dendritic cells via a short CD11c promoter sequence. Vaccine 2009, 27(40):5480-5487.

18. Bonkobara M, Zukas PK, Shikano S, Nakamura S, Cruz PD Jr, Ariizumi K: Epidermal Langerhans cell-targeted gene expression by a dectin-2 promoter. J Immunol 2001, 167(12):6893-6900.

19. Kimura $T$, Koya RC, Anselmi L, Sternini C, Wang HJ, Comin-Anduix B, Prins RM, Faure-Kumar E, Rozengurt N, Cui Y, Kasahara N, Stripecke R: Lentiviral vectors with CMV or MHCII promoters administered in vivo: immune reactivity versus persistence of expression. Mol Ther 2007, 15(7):1390-1399

20. Brocker $T$, Riedinger $M$, Karjalainen $K$ : Driving gene expression specifically in dendritic cells. Adv Exp Med Biol 1997, 417:55-57.

21. Hon H, Oran A, Brocker T, Jacob J: B lymphocytes participate in crosspresentation of antigen following gene gun vaccination. J Immunol 2005, 174(9):5233-5242.

22. Lauterbach $\mathrm{H}$, Gruber A, Ried C, Cheminay C, Brocker T: Insufficient APC capacities of dendritic cells in gene gun-mediated DNA vaccination. $J$ Immunol 2006, 176(8):4600-4607.

23. Pozzi LA, Maciaszek JW, Rock KL: Both dendritic cells and macrophages can stimulate naive CD8 T cells in vivo to proliferate, develop effector function, and differentiate into memory cells. J Immunol 2005, 175(4):2071-2081.

24. Kovacsovics-Bankowski M, Clark K, Benacerraf B, Rock KL: Efficient major histocompatibility complex class I presentation of exogenous antigen upon phagocytosis by macrophages. Proc Natl Acad Sci USA 1993, 90(11):4942-4946.

25. Constant S, Schweitzer N, West J, Ranney P, Bottomly K: B lymphocytes can be competent antigen-presenting cells for priming CD4+ T cells to protein antigens in vivo. J Immunol 1995, 155(8):3734-3741.

26. Ducrest AL, Amacker M, Lingner J, Nabholz M: Detection of promoter activity by flow cytometric analysis of GFP reporter expression. Nucleic Acids Res 2002, 30(14):e65.

27. Weeratna RD, Wu T, Efler SM, Zhang L, Davis HL: Designing gene therapy vectors: avoiding immune responses by using tissue-specific promoters. Gene Ther 2001, 8(24):1872-1878.

28. Billingsley KG, Fraker DL, Strassmann G, Loeser C, Fliot HM, Alexander HR: Macrophage-derived tumor necrosis factor and tumor-derived of leukemia inhibitory factor and interleukin-6: possible cellular mechanisms of cancer cachexia. Ann Surg Oncol 1996, 3(1):29-35.

29. Tamura K, Dudley J, Nei M, Kumar S: Molecular Evolutionary Genetics Analysis [MEGA] software version 4.0. Mol Biol Evol 2007, 24(8):1596-1599.

30. Li AC, Guidez FR, Collier JG, Glass CK: The macrosialin promoter directs high levels of transcriptional activity in macrophages dependent on combinatorial interactions between PU.1 and c-Jun. J Biol Chem 1998, 273(9):5389-5399.
31. Rabinowitz SS, Gordon S: Macrosialin, a macrophage-restricted membrane sialoprotein differentially glycosylated in response to inflammatory stimuli. J Exp Med 1991, 174(4):827-836.

32. Holness CL, da Silva RP, Fawcett J, Gordon S, Simmons DL: Macrosialin, a mouse macrophage-restricted glycoprotein, is a member of the lamp/ Igp family. J Biol Chem 1993, 268(13):9661-9666.

33. O'Reilly D, Addley M, Quinn C, MacFarlane AJ, Gordon S, McKnight AJ, Greaves DR: Functional analysis of the murine Emr1 promoter identifies a novel purine-rich regulatory motif required for high-level gene expression in macrophages. Genomics 2004, 84(6):1030-1040.

34. Schaller E, Macfarlane AJ, Rupec RA, Gordon S, McKnight AJ, Pfeffer K: Inactivation of the F4/80 glycoprotein in the mouse germ line. Mol Cell Biol 2002, 22(22):8035-8043

35. McKnight AJ, Macfarlane AJ, Dri P, Turley L, Willis AC, Gordon S: Molecular cloning of $\mathrm{F} 4 / 80$, a murine macrophage-restricted cell surface glycoprotein with homology to the G-protein-linked transmembrane 7 hormone receptor family. J Biol Chem 1996, 271(1):486-489.

36. Hirsch S, Austyn JM, Gordon S: Expression of the macrophage-specific antigen F4/80 during differentiation of mouse bone marrow cells in culture. J Exp Med 1981, 154(3):713-25.

37. Feng X, Teitelbaum SL, Quiroz ME, Cheng SL, Lai CF, Avioli LV, Ross FP: Sp1/Sp3 and PU.1 differentially regulate beta[5] integrin gene expression in macrophages and osteoblasts. J Biol Chem 2000, 275(12):8331-8340

38. Feng X, Teitelbaum SL, Quiroz ME, Towler DA, Ross FP: Cloning of the murine beta5 integrin subunit promoter. Identification of a novel sequence mediating granulocyte-macrophage colony-stimulating factordependent repression of beta5 integrin gene transcription. J Biol Chem 1999, 274(3):1366-1374

39. Boshart M, Weber F, Jahn G, Dorsch-Häsler K, Fleckenstein B, Schaffner W: A very strong enhancer is located upstream of an immediate early gene of human cytomegalovirus. Cell 1985, 41(2):521-530.

40. Mizuguchi H, Xu ZL, Sakurai F, Mayumi T, Hayakawa T: Tight positive regulation of transgene expression by a single adenovirus vector containing the rtTA and tTS expression cassettes in separate genome regions. Hum Gene Ther 2003, 14(13):1265-1277.

41. Ross R, Sudowe S, Beisner J, Ross XL, Ludwig-Portugall I, Steitz J, Tüting T, Knop J, Reske-Kunz AB: Transcriptional targeting of dendritic cells for gene therapy using the promoter of the cytoskeletal protein fascin. Gene Ther 2003, 10(12):1035-1040.

42. Glenting J, Wessels S: Ensuring safety of DNA vaccines. Microb Cell Fact 2005, 4:26.

43. Furtado A, Henry R: Measurement of green fluorescent protein concentration in single cells by image analysis. Anal Biochem 2002, 310(1):84-92.

44. Shen Y, lqbal J, Huang JZ, Zhou G, Chan WC: BCL2 protein expression parallels its mRNA level in normal and malignant B cells. Blood 2004, 104(9):2936-2939.

doi:10.1186/1479-0556-9-10

Cite this article as: Ahsan and Gore: Comparative analysis of macrophage associated vectors for use in genetic vaccine. Genetic Vaccines and Therapy 2011 9:10.

\section{Submit your next manuscript to BioMed Central and take full advantage of:}

- Convenient online submission

- Thorough peer review

- No space constraints or color figure charges

- Immediate publication on acceptance

- Inclusion in PubMed, CAS, Scopus and Google Scholar

- Research which is freely available for redistribution

Submit your manuscript at www.biomedcentral.com/submit
C Biomed Central 